\title{
Quantitative evaluation of bone development of the distal phalanx of the cow hind limb using computed tomography
}

\author{
T. Tsuka, ${ }^{, 1}$ K. Ooshita,† A. Sugiyama, ${ }^{*}$ T. Osaki, ${ }^{*}$ Y. Okamoto, ${ }^{\star}$ S. Minami, ${ }^{*}$ and T. Imagawa ${ }^{\star}$ \\ *Department of Veterinary Clinical Medicine, School of Veterinary Medicine, Faculty of Agriculture, Tottori University, Tottori, Japan, 680-8550 \\ †Hatsukaichi Veterinary Clinic, Hiroshima Prefectural Federation Agricultural Mutual Aid Association, Hatsukaichi, Japan, 738-8799
}

\begin{abstract}
Computed tomography (CT) was performed on 400 claws (200 inner and 200 outer claws) of 100 pairs of bovine hind limbs to investigate the etiological theory that an exacerbating factor for ulceration is exostosis of the tuberculum flexorium within the distal phalanx. A variety of morphological changes of the tuberculum flexorium of bovine hind limb claws was visualized by 3-dimensional $\mathrm{CT}$, and the geometry of these claws suggested a growth pattern of bone development with respect to the assumed daily loading patterns. This growth occurs initially at the abaxial caudal aspect of the distal phalanx and is followed by horizontal progression toward the axial aspect. The length of downward bone development on the solar face of the distal phalanx was $2.73 \pm 1.32 \mathrm{~mm}$ in the outer claws, significantly greater than in the inner claws $(2.38 \pm$ $0.96 \mathrm{~mm}$ ). Ratios of downward (vertical) bone development to the thickness of the subcutis and the corium (VerBD ratios) did not differ between the outer and inner claws (36.7 vs. $38.3 \%$, respectively). Ratios of horizontal bone development to the axial-to-abaxial line of the tuberculum flexorium (HorBD ratios) were approximately $60 \%$ for both outer and inner claws. These quantitative measures regarding horizontal and vertical bone development within the distal phalanx were positively correlated with age and VerBD ratios $(\mathrm{r}=0.53$ and $\mathrm{r}=0.36$ for the inner and outer claws, respectively). Correlations between claw width of the outer claw and length of vertical bone development ( $\mathrm{r}$ $=0.43)$, the HorBD ratio $(\mathrm{r}=0.51)$, and the VerBD ratio $(\mathrm{r}=0.42)$ suggested that the relative size difference between the inner and outer claws enhances bone development in the outer claw. Correlation coefficients between VerBD and HorBD ratios $(r=0.52$ and 0.63 for the inner and outer claws, respectively) suggested that horizontal and vertical bone development occurs as a synchronized process within the tuberculum flexo-
\end{abstract}

\footnotetext{
Received February 27, 2011.

Accepted September 29, 2011.

${ }^{1}$ Corresponding author: tsuka@muses.tottori-u.ac.jp
}

rium. This age-related progress of bone development within the tuberculum flexorium is associated with increased exposure to several exacerbating factors and the laminitic process.

Key words: computed tomography, dairy herd, enthesopathy, tuberculum flexorium

\section{INTRODUCTION}

Lameness inflicts considerable damage on affected herds of cows, and can cause financial loss due to decreased milk production, increased BW loss, death, culling, and decreased reproductive performance (Greenough and Vermunt, 1991; Singh et al., 1994; van der Tol et al., 2004). Reported estimates of annual incidence rates of lameness in herds vary from 4 to 25\% (Vermunt and Greenough, 1995). About 92\% of lesions associated with episodes of lameness occur in the hind limbs, and $65 \%$ of hind leg lameness occurs in the outer claw (Murray et al., 1996; Nuss and Paulus, 2006). The most common horn disease is sole ulcer, with an incidence of 3 to $28 \%$ (Holzhauer et al., 2008). When classified according to the zones proposed by Greenough and Vermunt (1991), ulcers typically occur on the axial part of the sole surface (zone 4) and the heel (zone 6). Compression damage of the corium occurs readily in these zones because the distal phalanx drops both in the downward direction and toward the axial wall of the hoof (Maclean, 1970; Lischer et al., 2002; van Amstel and Shearer, 2006). These zones are directly beneath the tuberculum flexorium of the distal phalanx, the ventral surface of the distal phalanx in the region of the insertion of the deep digital flexor tendon (Blowey et al., 2000; Desrochers and Anderson, 2001). The tuberculum flexorium possesses a natural downward protruding structure and is anatomically involved in the pathogenesis of sole ulcer (Desrochers and Anderson, 2001). Moreover, it is one of the typical regions in which exostosis occurs, in addition to the facies flexoria of the distal sesamoid bone and inter-digital joints (Maclean, 1970; Desrochers and Anderson, 2001; Müller et al., 2002). Exostosis leads to the more protruded structure of the tuberculum flexorium (Maclean, 1970). 
Therefore, exostosis of the distal phalanx is believed to be an exacerbating factor for ulcer formation (Blowey et al., 2000; Lischer et al., 2002). Mechanical damage of the corium layer due to the exostosis in the tuberculum flexorium is evident by sole hemorrhage and necrosis of the corium (Blowey et al., 2000).

Few studies have performed detailed evaluations of the relationship between exostosis of the tuberculum flexorium and early ulceration in the claws of healthy and affected cattle (Maclean, 1970). The best evaluations for verification of this relationship have been obtained using radiography, which enables visualization of morphological abnormalities of the bone such as ossification and osteolysis (Maclean, 1970; Farrow, 1985). The use of radiography in evaluation can be limited when the outer and inner claw overlap on the lateral view. Radiography provides only a planar (2-dimensional, 2D) view and has limited value in soft tissue evaluation (Farrow, 1985; Raji et al., 2008). Ultrasonography provides a small field of view and unclear visualization of soft tissue (Kofler et al., 1999), and cannot pass through the bones of the digits (Raji et al., 2008). Only a few reports exist of the application of computed tomography (CT) to bovine claws (Kofler et al., 1999; Raji et al., 2008). Computed tomography provides 2D images of objects and, through the reconstruction of consecutive scans, these images can be built up into 3-dimensional (3D) images that present views from every direction. The 3D images provide detailed visualization of morphological features within the horn capsule and enable the observation of horn formation. Moreover, the anatomical relationship between the morphological features of the tuberculum flexorium (e.g., change in shape and the protruded level due to bone development) and the soft tissues (the corium) can be evaluated using a clear visual distinction of the structures inside the claw horn on CT images, although the evaluation is difficult using radiographic analysis. The present study shows characteristic CT images of bone development (with respect to the assumed daily loading patterns) within the tuberculum flexorium, which were classified into 4 phases based on the severity of the osseous changes. Bone development within the tuberculum flexorium was then evaluated using quantitative measures to represent vertical and horizontal progression. Correlations between these bone growth measures, differences between the outer and inner claws and between floor types (housing groups), and differences with age were investigated.

\section{MATERIALS AND METHODS}

Specimens were 100 pairs of hind limbs that had been amputated at the ankle. The phalanges of the hind limbs were soaked in hot water (approximately $70^{\circ} \mathrm{C}$ ) for $30 \mathrm{~min}$ before being separated from the horn capsule. All hind limbs were from lactating Holstein cows obtained from a slaughterhouse (Tottori Meat Inspection Center, Tottori Prefectural Government, Tottori, Japan); the age of the cattle ranged from 23 to 143 mo. The 100 cows were housed in 1 of 2 types of conditions: 67 were housed in tie-stall barns ( $\mathbf{T}$ group; age: $58.5 \pm 24.4 \mathrm{mo}$ ), and 33 were housed in freestall barns or indoor group-housing ( $\mathbf{F}$ group; age: $57.9 \pm$ $21.9 \mathrm{mo}$ ). Sole ulcers were observed on 9 outer claws of 7 cows in $\mathrm{T}$ (age: $86.1 \pm 25.3 \mathrm{mo}$ ). The prevalence of sole ulcers was $10.4 \%(7 / 67)$ in the $\mathrm{T}$ group $(7 \%$ in all 100 cows). Information regarding clinical history (i.e., whether the animal had ever suffered claw problems or lameness) was unavailable for all animals.

\section{CT Imaging Procedures}

The CT device used was a slip-ring scanner (Pronto SE, Hitachi Co. Ltd., Tokyo, Japan). The x-ray tube was operated at 100 or $120 \mathrm{kVp}$ and a current of 100 $\mathrm{mA}$. The scanning measures were 2.5 -mm slice thickness and $2.5-\mathrm{mm} / \mathrm{s}$ table speed. The specimen was placed on the table with the dorsal surface down, and oriented transverse to the scanning plane. The 3D reconstruction was performed through an image analysis system (AZE Virtual Place, AZE Corp., Tokyo, Japan). Plantar-dorsal and lateral 3D images were used to evaluate the magnitude of bone development. Mid-sagittal 2D images were obtained by reconstructing the $3 \mathrm{D}$ images.

\section{Measurement of Claw Conformation Parameters}

Measurements of the claw horn were performed using 4 quantitative traits according to Vermunt and Greenough (1995): toe angle (obtained from the slope of the dorsal border of the claw with respect to the sole surface); toe length (obtained from the distance from the periople to the apex of the claw on the dorsal border); heel height (obtained from the vertical distance from the sole surface to the skin-horn junction); and claw width of the outer and inner claws (obtained from the largest distance between the abaxial and axial wall of the claw at the sole-bulb junction). Toe angles were measured using analysis of the lateral 3D images. Toe length, heel height, and claw width of both claws were measured grossly using a caliper. Measurements of toe angle, toe length, and heel height could not be done, respectively, in 1,2, and 1 outer claws because of severe abnormal shapes of the claws. The average toe angle, toe length, heel height, and inner and outer claw widths were (range in parentheses) $46.0 \pm 5.2^{\circ}\left(28\right.$ to $\left.62^{\circ}\right), 81.3$ $\pm 9.7 \mathrm{~mm}$ (60 to $141 \mathrm{~mm}$ ), $40.2 \pm 10.0 \mathrm{~mm}$ (16 to 76 


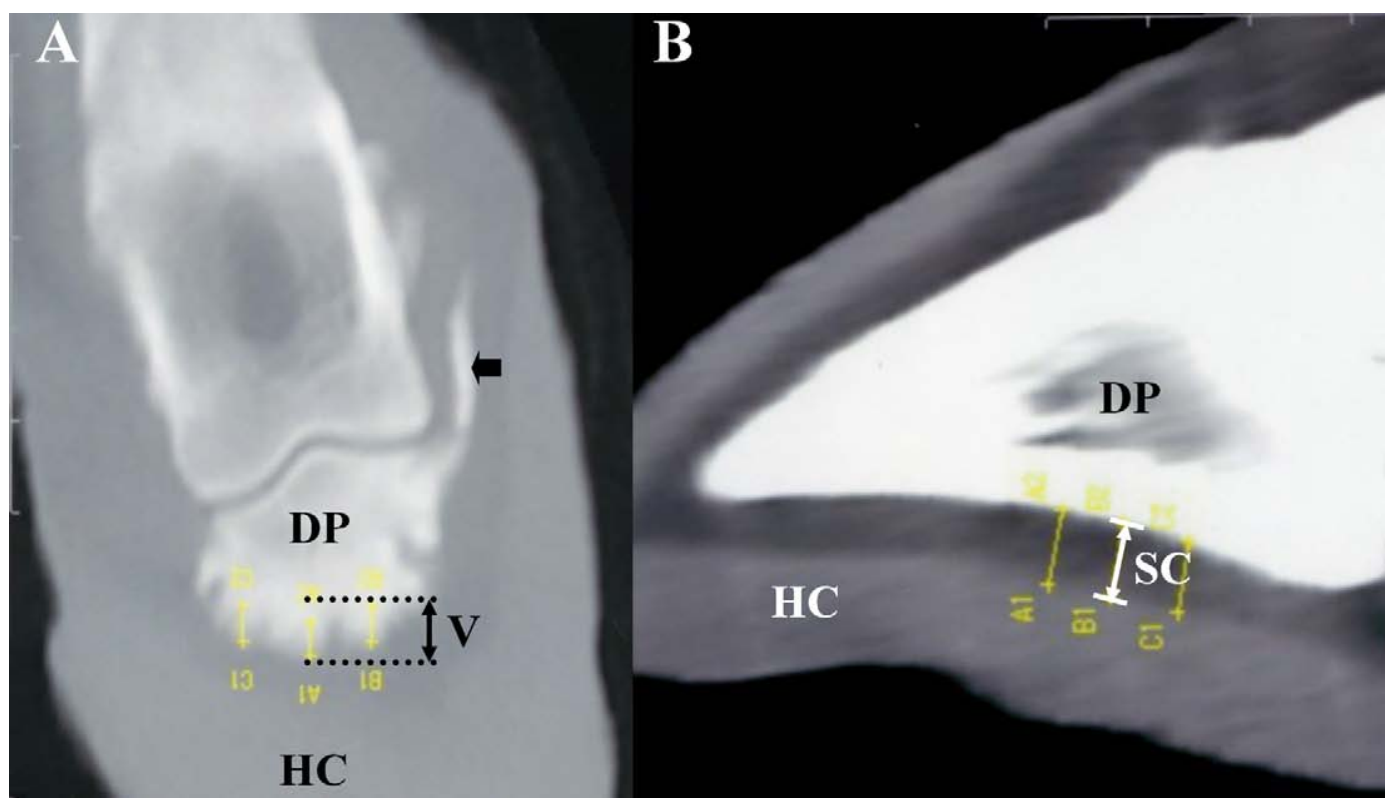

Figure 1. (A) Basic transverse computed tomographic (CT) image used to measure the length of vertical (downward) bone development (V). This claw was acquired from the same cow shown in Figures 3 and 4D. Arrow shows upward bone formation at the abaxial region. (B) Basic mid-sagittal CT used to measure the thickness of the subcutis and the corium (SC) under the middle site of the distal phalanx. Ratios of vertical bone development (VerBD ratio) were obtained by V/SC $\times 100(\%)$. DP = distal phalanx; HC $=$ horn capsule. Scale $=10 \mathrm{~mm}$. Color version available in the online $\mathrm{PDF}$.

$\mathrm{mm}), 50.4 \pm 4.0 \mathrm{~mm}(40$ to $65 \mathrm{~mm})$, and $57.0 \pm 5.3$ $\mathrm{mm}(47$ to $86 \mathrm{~mm})$, respectively.

\section{Measurement of Bone Development}

Four quantitative measures were investigated on the tuberculum flexorium: length of vertical bone development (VerBD), thickness of the subcutis and the corium, horizontal bone development (HorBD) ratio, and VerBD ratio. Length of VerBD was evaluated on transverse CT images (Figure 1A). These images demonstrate a soft tissue layer composed of the subcutis and the corium in the space between the distal phalanx and the horn capsule. Length of VerBD was obtained by measurement of the most protruded region within the ventral surface of the distal phalanx (site of tuberculum flexorium). Thickness of the subcutis and the corium was evaluated on a mid-sagittal image (Figure 1B). This image shows the frontal-caudal sagittal section of the distal phalanx, the soft tissue layer of the subcutis and the corium, and the horn capsule, although the visual distinction between the subcutis and the corium is difficult. Thickness of the subcutis and the corium was acquired from measurement of the distance between the ventral surface of the distal phalanx and the inner surface of the horn capsule in the middle of the distal phalanx, according to Lischer et al. (2002). The VerBD ratio against the subcutis and the corium was calculated as follows: VerBD ratio (\%) $=$ (length of vertical bone development/thickness of the subcutis and the corium $) \times 100$. The HorBD ratio was evaluated on a plantar-dorsal 3D-CT view of the distal phalanx (Figure 2). This image shows the axialto-abaxial caudal margin of the tuberculum flexorium. The HorBD ratio was obtained by the ratio of horizontally protruded bones to axial-to-abaxial margin of the tuberculum flexorium.

\section{Statistical Analyses}

Three statistical analyses were performed. Four quantitative measures (length of VerBD, thickness of the subcutis and corium, HorBD ratio, and VerBD ratio) were investigated using the mean \pm standard deviation (SD) values from 200 inner claws and 191 outer claws from 100 cows, excluding the 9 outer claws of the 7 cows with sole ulcers. The data were analyzed by ANOVA as a $2 \times 2$ factorial design, to compare bone development measures between the inner and outer claws, and between the 2 types of housing conditions ( $\mathrm{T}$ group, $\mathrm{n}=67$; and $\mathrm{F}$ group, $\mathrm{n}=33$ ). Quantitative data from the sole ulcer group (in the 9 outer claws of $7 \mathrm{~T}$ group cows) were statistically investigated for the above-mentioned comparisons with total values of both claws, for the 2 housing groups, and for all cows using ANOVA. 
Pearson correlation coefficients $(\mathrm{r})$ and $P$-values were calculated to assess statistical relationships between age and the above-mentioned quantitative bone development data for both the inner and outer claws, and between 4 claw conformation measures and the 4 quantitative bone development measures for both the inner and outer claws. Pearson correlation coefficients and $P$-values were calculated to assess relationships between HorBD ratios and VerBD ratios for both the inner and outer claws.

All statistical analyses were used for investigations of differences between the $\mathrm{T}$ group $(\mathrm{n}=67), \mathrm{F}$ group $(\mathrm{n}=33)$, and all 100 cows. A $P$-value of $<0.01$ was considered statistically significant.

\section{RESULTS}

\section{Characteristics of Bone Development on CT Images}

Examples of morphological findings of bone development on 3D-CT images of the distal phalanx and gross appearance were divided into 4 phases: no bone development (Figures 3A and 4A), small amount of bone development (Figures $3 \mathrm{~B}$ and $4 \mathrm{~B}$ ), moderate amount of bone development (Figures $3 \mathrm{C}$ and $4 \mathrm{C}$ ), and extensive bone development (Figures 3D and 4D). The inner claw of the left rear limb from a 26-mo-old animal showed no bone development. Relevant measurements were as follows: toe angle, $45^{\circ}$; toe length, $83 \mathrm{~mm}$; heel height, $36 \mathrm{~mm}$; and claw width, $47 \mathrm{~mm}$. No gross claw lesions were observed after trimming. On the plantardorsal CT view (Figure $3 \mathrm{~A} 1$ ) and on gross appearance (Figure 3 A2), the ventral surface was smooth at the tuberculum flexorium, and both the axial and abaxial caudal aspects of the distal phalanx appeared rounded. The axial-to-abaxial margin of the caudal aspect appeared almost straight. On the lateral CT view (Figure 4 A1) and on gross appearance (Figure 4 A2), the sole line was demonstrated as flat, without protrusion of newly formed bone.

The outer claw of the left rear leg of a 69-mo-old animal showed a small amount of bone development. Relevant measurements were as follows: toe angle, $48^{\circ}$; toe length, $86 \mathrm{~mm}$; heel height, $49 \mathrm{~mm}$; and claw width, $66 \mathrm{~mm}$. No gross claw lesions were observed after trimming. These changes were characterized by bone growth on the abaxial caudal aspect of the distal phalanx and growth horizontally against the sole on the plantar-dorsal CT view (Figure 3 B1). A wave-like bone development was grossly observed in the ventral surface on the abaxial side of the distal phalanx (Figure 3 B2). Vertical progressions were not observed on the lateral $\mathrm{CT}$ view (Figure $4 \mathrm{~B} 1$ ) and on the gross appearance (Figure 4 B2).

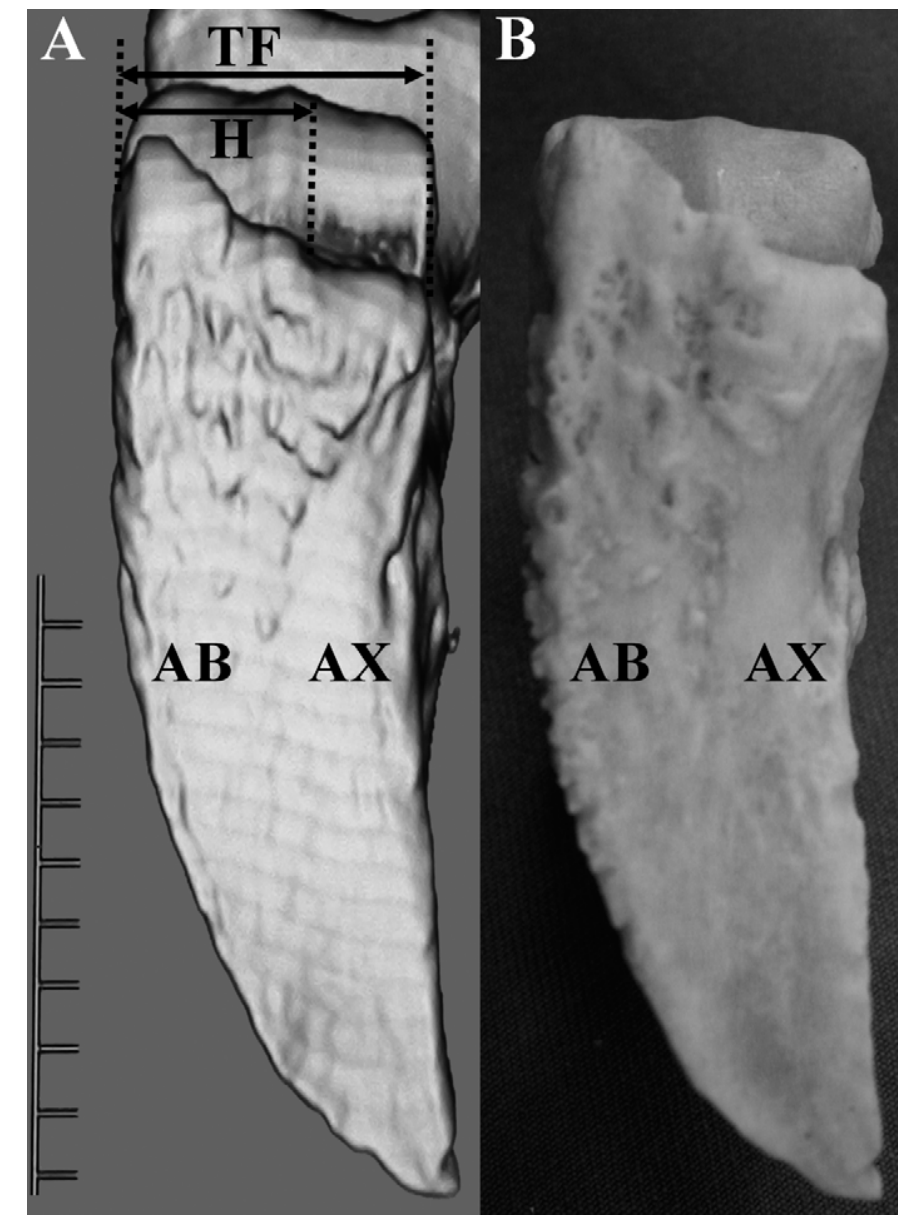

Figure 2. Basic plantar-dorsal 3-dimensional computed tomographic (3D-CT) images and gross appearance used to measure the ratios of horizontal bone development (HorBD ratio). This claw was the outer claw of the right rear limb of an 89-mo-old animal, and had moderate new bone formation. The HorBD ratio was obtained by the ratio of horizontally protruded bones $(\mathrm{H})$ to the axial-to-abaxial line of the tuberculum flexorium $(\mathrm{TF}$; ratio: $\mathrm{H} / \mathrm{TF} \times 100 \%) . \mathrm{AB}=$ abaxial region; $\mathrm{AX}=$ axial region. Scale $=5 \mathrm{~mm}$.

The inner claw of the left rear leg of an 82-mo-old animal showed a moderate amount of bone development. Relevant measurements were as follows: toe angle, $48^{\circ}$; toe length, $75 \mathrm{~mm}$; heel height, $42 \mathrm{~mm}$; and claw width, $56 \mathrm{~mm}$. On the plantar-dorsal CT view (Figure $3 \mathrm{C} 1$ ), the ventral surface of the distal phalanx appeared irregular, predominantly on the abaxial side of the tuberculum flexorium. The axial-to-abaxial line of the caudal region appeared double-peaked due to bone development that enlarged the middle and lateral sides of the caudal aspect. Bone growth was seen together with osteolytic changes on the surface of the bottom of the distal phalanx (Figure $3 \mathrm{C} 2$ ). On the lateral CT view (Figure $4 \mathrm{C} 1$ ) and on the gross appearance (Figure $4 \mathrm{C} 2$ ), the sole surface appeared moderately irregular with slight vertical protrusion. 

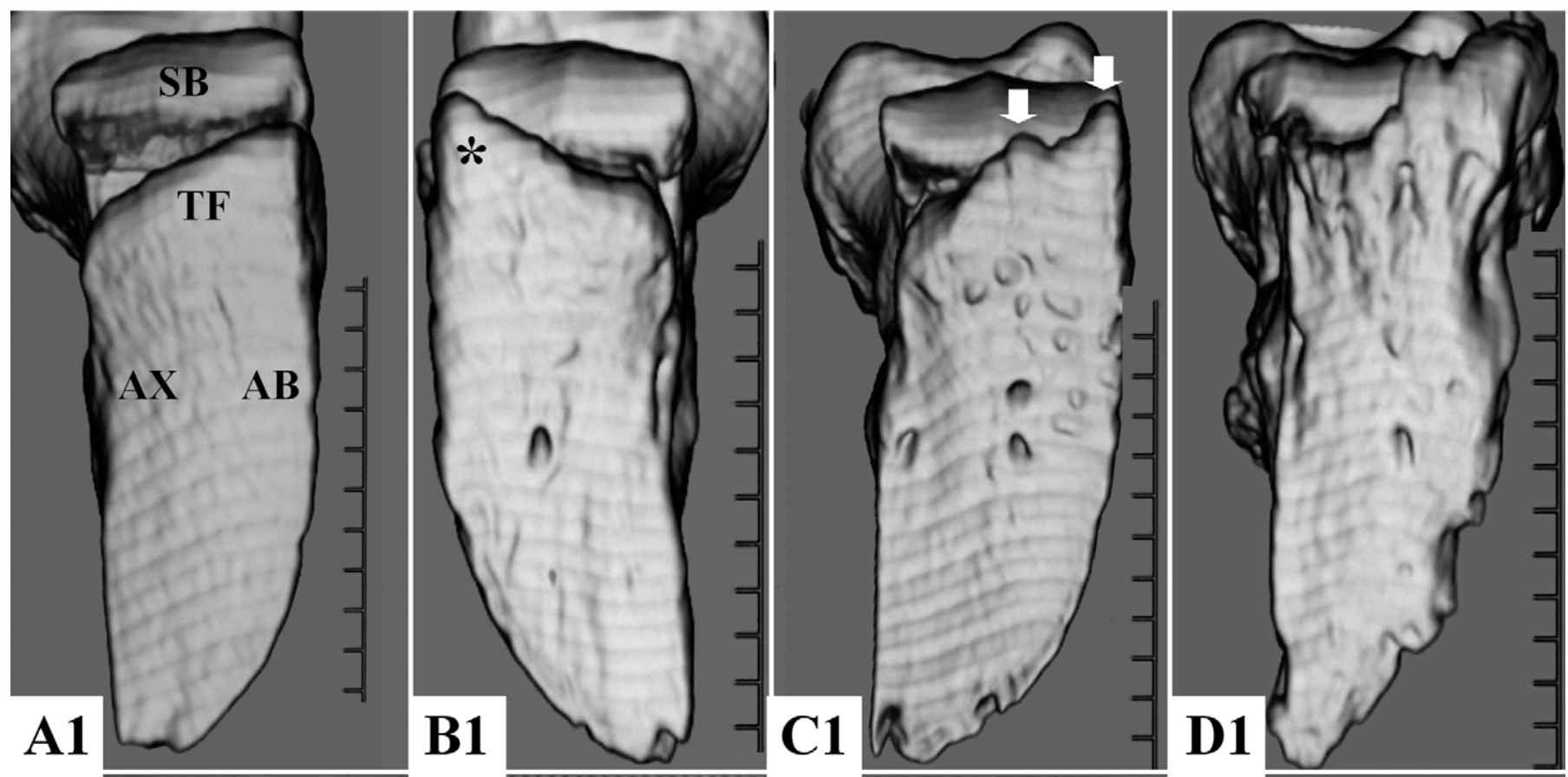

\section{A2}
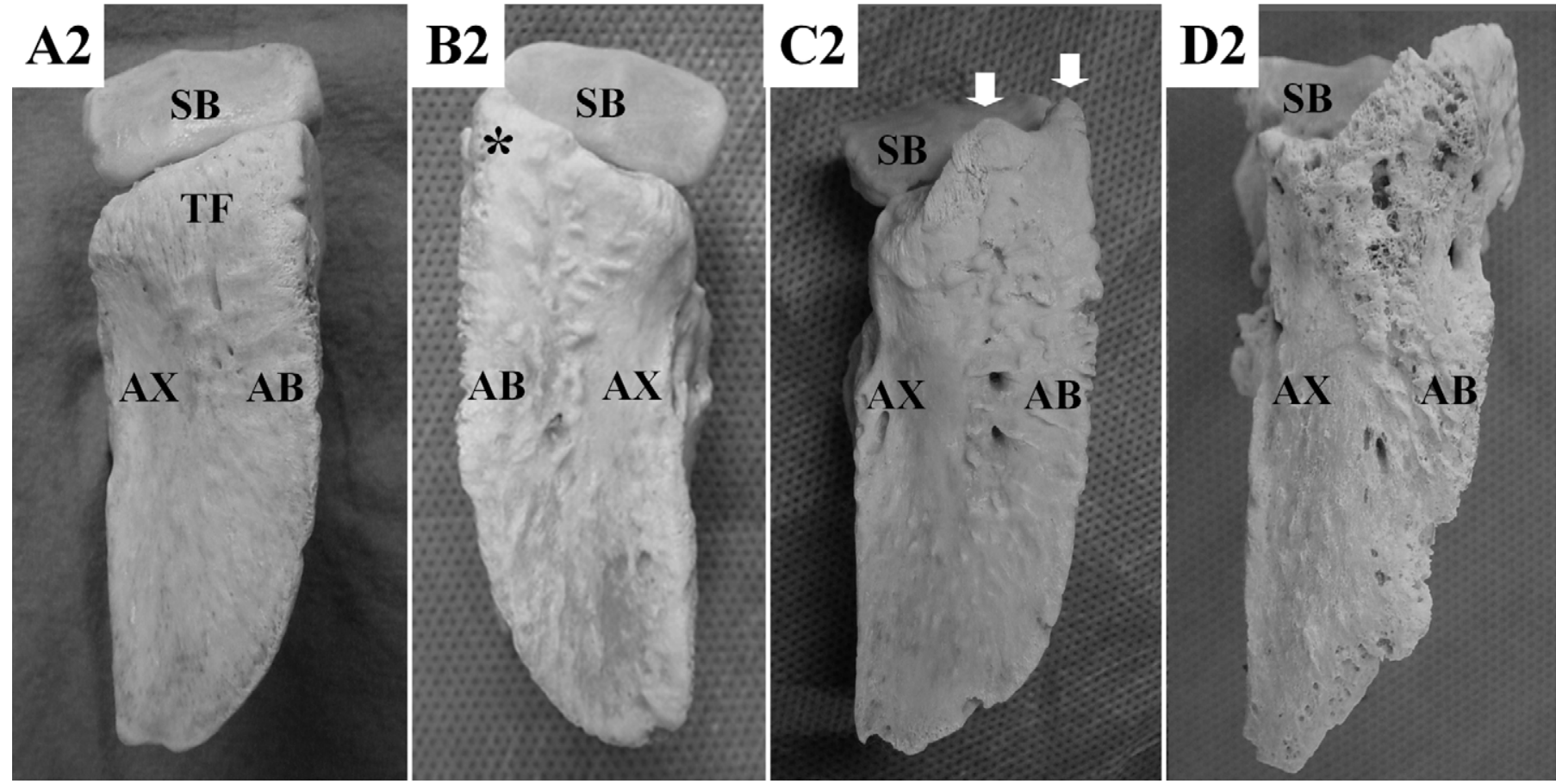

Figure 3. Plantar-dorsal 3-dimensional computed tomographic (3D-CT) images and gross appearances showing abaxial-to-axial bone development within the distal phalanx. A1 and A2: 3D-CT and gross appearance of a cow with no bone formation reveals a smooth ventral surface and rounded axial and abaxial aspects of the tuberculum flexorium (TF). B1 and B2: 3D-CT and gross appearance of a cow with a small amount of bone formation reveals a rounded peaked sign at the lateral aspect of the tuberculum flexorium (asterisk). C1 and C2: 3D-CT and gross appearance of a cow with a moderate amount of bone formation reveals irregularities at the ventral surface and a double-peaked sign at both the middle part and lateral aspect of the tuberculum flexorium (2 arrows). D1 and D2: 3D-CT and gross appearance of a cow with extensive bone formation reveals obliteration of the original surface of the bone due to the protruded bones. $\mathrm{AB}=$ abaxial region; $\mathrm{AX}=\mathrm{axial}$ region; $\mathrm{SB}=$ distal sesamoid bone. Scale $=5 \mathrm{~mm}$.

The outer claw of the right rear leg of a 128-mo-old animal showed extensive bone development. Relevant measurements were as follows: toe angle, $57^{\circ}$; toe length, $100 \mathrm{~mm}$; heel height, $69 \mathrm{~mm}$; and claw width, $63 \mathrm{~mm}$. The claw was boot-like in shape. Severe interdigital dermatitis was observed, but no sole ulcer was 

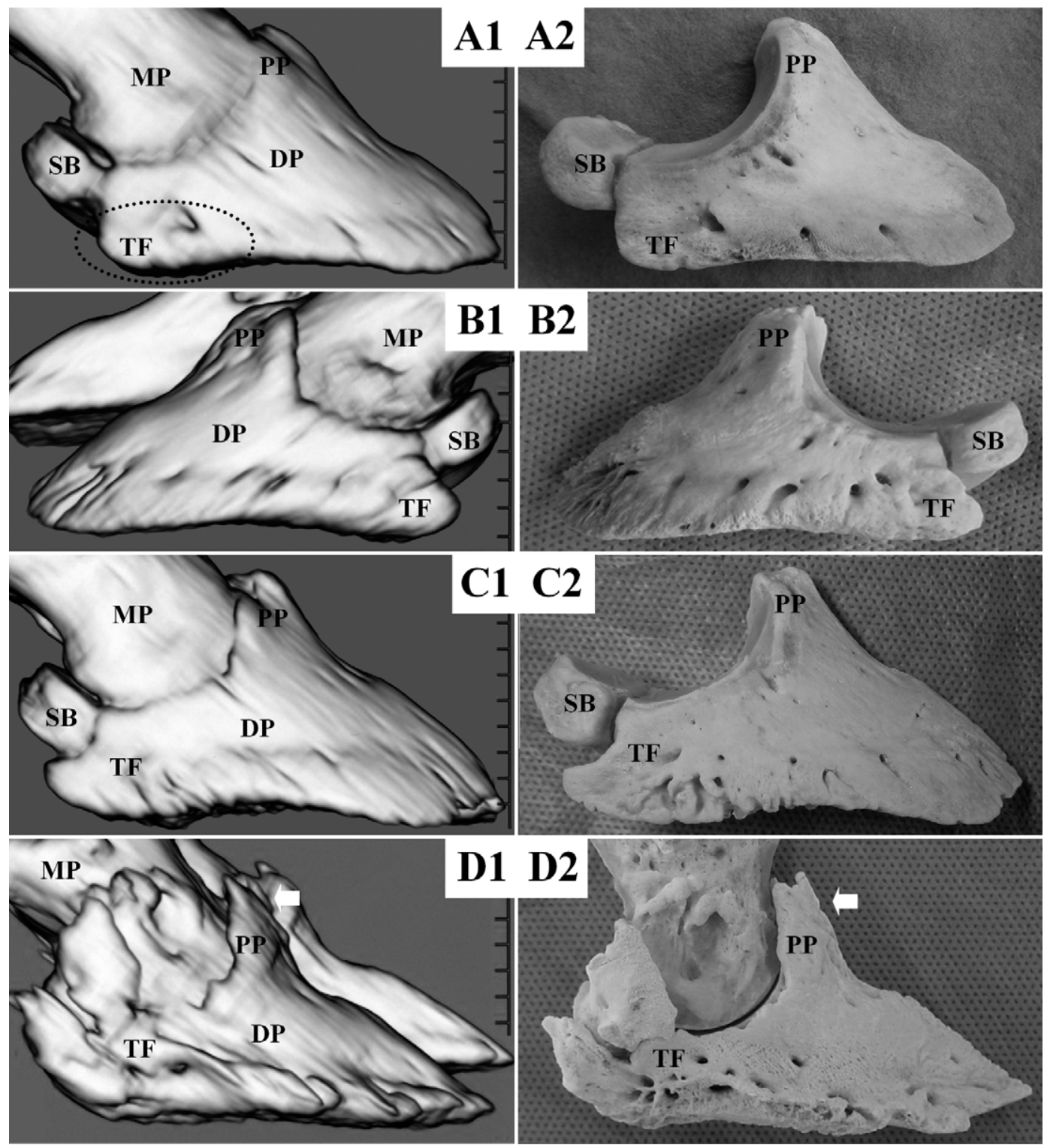

Figure 4. Lateral 3-dimensional computed tomographic (3D-CT) images and gross appearances showing downward bone development within the distal phalanx. A1 and A2: 3D-CT and gross appearance of a cow with no bone formation (shown in Figure 3 A1 and A2) reveals a flat sole line without the protruded bones (within a gray broken ring). B1 and B2: 3D-CT and gross appearance of a cow with a small amount of bone formation (shown in Figure $3 \mathrm{~B} 1$ and B2) reveals a flat sole line without the protruded bones. C1 and C2: 3D-CT and gross appearance of a cow with a moderate amount of bone formation (shown in Figure $3 \mathrm{C} 1$ and $\mathrm{C} 2$ ) reveals moderate irregularity at the sole line with slight vertical protrusion. D1 and D2: 3D-CT and gross appearance of a cow with extensive bone formation (shown in Figure 3 D1 and D2) reveals the surface of intact bone that has been covered by the formed bone within the tuberculum flexorium (TF) and the pyramidal process $($ arrow). DP $=$ distal phalanx; $\mathrm{MP}=$ middle phalanx; $\mathrm{PP}=$ pyramidal process; $\mathrm{SB}=$ distal sesamoid bone. Scale $=5 \mathrm{~mm}$.

found. On the plantar-dorsal 3D-CT view, we observed extensive bone growth in the frontal-caudal direction, which replaced half of the original surface of the distal phalanx (Figure 3 D1). On the lateral 3D-CT view, the bone covered the ventral surface of the distal phalanx (Figure 4 D1). Bone growth was observed on the superior region including the pyramidal process (the point of insertion of the main digital extensor tendon) as well as on the inferior region. The growth toward the caudal side allowed osseous adherence across the space between the distal phalanx and distal sesamoid bone. On the transverse view, upward bone development was observed on the abaxial region of the distal phalanx (Figure 1A). These pathological changes prevented free articulation between the middle and distal phalanges. After removing the horn capsule, internal hemorrhage 
Table 1. Mean $( \pm \mathrm{SD})$ of bone development measures in the inner and outer claws of tie-stall housing cow (T group), freestall or indoor grouphousing cows ( $\mathrm{F}$ group), and total cows

\begin{tabular}{|c|c|c|c|c|c|c|}
\hline \multirow{2}{*}{$\begin{array}{l}\text { Housing } \\
\text { group }\end{array}$} & \multicolumn{3}{|c|}{ Length of vertical bone development (mm) } & \multicolumn{3}{|c|}{ Thickness of subcutis and corium (mm) } \\
\hline & Inner claws & Outer claws & Total & Inner claws & Outer claws & Total \\
\hline $\mathrm{T}$ & $2.37 \pm 1.00$ & $2.78 \pm 1.36$ & $2.57 \pm 1.20$ & $6.38 \pm 1.21$ & $6.98 \pm 1.23$ & $6.67 \pm 1.25$ \\
\hline $\mathrm{F}$ & $2.39 \pm 0.87$ & $2.64 \pm 1.25$ & $2.51 \pm 1.08$ & $7.00 \pm 0.83$ & $7.77 \pm 1.27$ & $7.39 \pm 1.14^{\mathrm{a}}$ \\
\hline Total & $2.38 \pm 0.96$ & $2.73 \pm 1.32^{\mathrm{b}}$ & $2.55 \pm 1.16$ & $6.59 \pm 1.14$ & $7.25 \pm 1.29^{\mathrm{b}}$ & $6.91 \pm 1.26$ \\
\hline Sole ulcer ${ }^{1}$ & & & $7.06 \pm 5.16^{\mathrm{c}}$ & & & $6.60 \pm 1.60$ \\
\hline
\end{tabular}

${ }^{\mathrm{a}}$ Value significantly greater in $\mathrm{F}$ group than in $\mathrm{T}$ group $(P<0.01)$.

${ }^{\mathrm{b}}$ Value for outer claws significantly greater than that for inner claws $(P<0.01)$.

${ }^{\mathrm{c}}$ Value significantly greater than those in both claws, F, T, and total cow groups $(P<0.01)$.

${ }^{1}$ Sole ulcer group comprised 9 outer claws of 7 cows with sole ulcers from the T group.

was observed on the heel region of the corium corresponding to the bone lesion. On the plantar-dorsal view of the gross appearance (Figure 3 D2), the surface of the growing bone on the bottom of the distal phalanx appeared rough, with numerous small openings due to osteolytic change. The structure was very fragile compared with the original bone. On the lateral view of the gross appearance (Figure 4 D2), bone development spread over the abaxial aspects of the distal and middle phalanges, and the distal sesamoid bone prevented free articulation between the middle and distal phalanges.

\section{Measurement of Bone Development}

Total length of VerBD in the outer claws $(2.73 \pm$ $1.32 \mathrm{~mm})$ was greater $(P<0.01)$ than that in the inner claws $(2.38 \pm 0.96 \mathrm{~mm}$; Table 1$)$. Lengths of VerBD were not significantly different between the $\mathrm{T}(2.57 \pm$ $1.20 \mathrm{~mm})$ and $\mathrm{F}(2.51 \pm 1.08 \mathrm{~mm})$ groups. Total value of the thickness of the subcutis and the corium was thicker $(P<0.01)$ in the outer claws $(7.25 \pm 1.29 \mathrm{~mm})$ than in the inner claws $(6.59 \pm 1.14 \mathrm{~mm})$. The $\mathrm{F}$ group $(7.39 \pm 1.14 \mathrm{~mm})$ had thicker $(P<0.01)$ subcutis and corium layers than the $\mathrm{T}$ group $(6.67 \pm 1.25 \mathrm{~mm})$. Total values of HorBD ratio were not significantly different between the inner claws $(59.6 \pm 13.2 \%)$ and the outer claws $(60.1 \pm 20.8 \%)$, or between the T group (60.5 \pm $19.2 \%)$ and the F group $(58.5 \pm 13.1 \%$; Table 2$)$. Total value of VerBD in the T group $(39.2 \pm 17.7 \%)$ was greater $(P<0.01)$ than that in the $\mathrm{F}$ group $(34.0 \pm$ $13.5 \%)$. The total value of VerBD ratio was not significantly different between the inner claws $(36.7 \pm 14.7 \%)$ and the outer claws $(38.3 \pm 18.4 \%)$. No interactions were found with a $2 \times 2$ factorial design between the claw groups (inner and outer claws) and housing groups ( $\mathrm{F}$ and $\mathrm{T}$ groups) in all bone development measures (length of VerBD, thickness of the subcutis and the corium, HorBD ratio, and VerBD ratio). The sole ulcer group had $7.06 \pm 5.16$ (2.0 to 18.1) $\mathrm{mm}$ of VerBD, 6.60 \pm 1.60 (3.8 to 9.3 ) $\mathrm{mm}$ in the thickness of the subcutis and the corium, a HorBD ratio of $108.4 \pm 39.2$ (52.8 to $161.5) \%$, and a VerBD ratio of $110.2 \pm 80.4$ (40.8 to $275.6) \%$. In the sole ulcer group, the length of VerBD, HorBD ratio, and VerBD ratio were greater $(P<0.01)$ than those of both claws, types of housing conditions, and total cow group.

Pearson correlation coefficients $(\mathrm{r}=0.65 ; P<0.01)$ were observed between age and length of VerBD within the inner claws of the $\mathrm{F}$ group (Table 3 ). Additionally, age and VerBD within the outer claws of the $\mathrm{F}$ group tended to show a correlation $(\mathrm{r}=0.53 ; P>$ 0.01 ). Thickness of the subcutis and the corium was not

Table 2. Mean $( \pm \mathrm{SD})$ of bone development measures in the inner and outer claws of tie-stall housing cows (T group), freestall or indoor grouphousing cows (F group), and total cows ${ }^{1}$

\begin{tabular}{|c|c|c|c|c|c|c|}
\hline \multirow[b]{2}{*}{ Group } & \multicolumn{3}{|c|}{ HorBD ratio $(\%)$} & \multicolumn{3}{|c|}{ VerBD ratio (\%) } \\
\hline & Inner claws & Outer claws & Total & Inner claws & Outer claws & Total \\
\hline $\mathrm{T}$ & $59.3 \pm 14.6$ & $61.9 \pm 23.1$ & $60.5 \pm 19.2$ & $37.9 \pm 15.7$ & $40.6 \pm 19.7$ & $39.2 \pm 17.7^{\mathrm{a}}$ \\
\hline $\mathrm{F}$ & $60.3 \pm 10.0$ & $56.8 \pm 15.4$ & $58.5 \pm 13.1$ & $34.1 \pm 12.4$ & $33.9 \pm 14.7$ & $34.0 \pm 13.5$ \\
\hline Total & $59.6 \pm 13.2$ & $60.1 \pm 20.8$ & $59.9 \pm 17.3$ & $36.7 \pm 14.7$ & $38.3 \pm 18.4$ & $37.5 \pm 16.6$ \\
\hline Sole ulcer ${ }^{2}$ & & & $108.4 \pm 39.2^{\mathrm{b}}$ & & & $110.2 \pm 80.4^{\mathrm{b}}$ \\
\hline
\end{tabular}

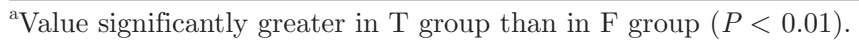

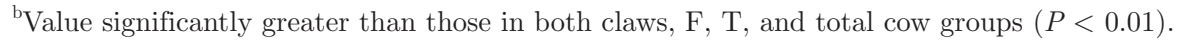

${ }^{1} \mathrm{HorBD}=$ ratio of horizontal bone development; VerBD = ratio of vertical bone development against the subcutis and the corium.

${ }^{2}$ Sole ulcer group comprised 9 outer claws of 7 cows with sole ulcers from the T group. 
significantly correlated with age in any group. Correlation coefficients were observed between age and HorBD ratio within the inner claws of the $\mathrm{T}$ group $(\mathrm{r}=0.53$; $P<0.01)$ and cows in combined housing ( $\mathrm{r}=0.51$; $P<0.01$ ), and between age and HorBD ratio within the outer claws of the $\mathrm{F}$ group $(\mathrm{r}=0.53 ; P<0.01)$. The VerBD ratio was correlated with age in the inner claws of the $\mathrm{F}$ group $(\mathrm{r}=0.68 ; P<0.01)$, and cows in combined housing $(\mathrm{r}=0.53 ; P<0.01)$. With the outer claws, the $\mathrm{F}$ group tended to have a correlation $(\mathrm{r}$ $=0.51 ; P<0.01)$. The relationships between age and VerBD ratio within inner claws (Figure 5A), and outer claws (Figure 5B) showed almost the same distribution as between the $\mathrm{T}$ group and $\mathrm{F}$ group. The VerBD ratios were almost below 40 and $50 \%$ in the inner and outer claws, respectively, in 2- to 3-yr-old cattle. In Figure $5 \mathrm{~B}$, data from the cows with sole ulcers $<8$ yr old are plotted above the distribution of the cows without sole ulcers.

No significant correlations were found between the 4 bone development measures and 4 claw conformation measures in the inner claw. In the outer claw, no significant correlations were found between 4 bone development measures and toe angle. The Pearson correlation coefficient between HorBD ratio and toe length $(\mathrm{r}=$ $0.25)$ was significant $(P<0.01)$ in the outer claws. Correlations were found between heel height and length of VerBD $(\mathrm{r}=0.21 ; P<0.01)$, HorBD ratio $(\mathrm{r}=0.31$; $P<0.01)$, and VerBD ratio $(\mathrm{r}=0.24 ; P<0.01)$ in the outer claws. Pearson correlation coefficients were observed between claw width of the outer claw and length of VerBD $(\mathrm{r}=0.43 ; P<0.01)$, HorBD ratio $(\mathrm{r}=0.51$; $P<0.01)$, and VerBD ratio $(\mathrm{r}=0.42 ; P<0.01)$. Claw width of the outer claw tended to be correlated with bone development measures except for thickness of the subcutis and the corium.

Pearson correlation coefficients between HorBD and VerBD ratios were significant $(P<0.01)$ for both the inner and outer claws of the $\mathrm{T}$ group $(\mathrm{r}=0.54$ and 0.63 , respectively), $\mathrm{F}$ group $(\mathrm{r}=0.49$ and 0.51 , respectively), and all cows ( $\mathrm{r}=0.52$ and 0.63 , respectively).
The relationships between HorBD and VerBD ratios within inner claws (Figure 6A) and outer claws (Figure $6 \mathrm{~B})$ showed almost the same distribution as between the $\mathrm{T}$ and $\mathrm{F}$ groups. The distribution of the outer claws was larger than that of the inner claws.

\section{DISCUSSION}

The applications of CT to bovine hind limbs in the current study clearly demonstrated the shape of the digit bone from every direction, in agreement with gross appearances. Another useful function of CT is the reconstruction of 2D as well as 3D images; mid-sagittal 2D images provided a clear visual distinction of the digit bone, the corium, and the horn capsule, and could be used for quantitative analyses. The applications of CT to bovine hind limbs revealed a high incidence of bone development in the distal phalanx of bovine claws obtained from a slaughterhouse. This result supports a previous study that reported the common occurrence of small exostoses on the tuberculum flexorium (Maclean, 1970). Exostoses of the middle phalanx can be categorized into 4 scores: immature, developing, mature, and hypermature (Farrow, 1985). In spite of regional differences in the digit bone (middle phalanx vs. distal phalanx), these processes of bone development likely occur within the distal phalanx, based on the morphological findings of the tuberculum flexorium. The slight osseous growths were characterized as one-sided formations on the lateral (abaxial) part of the distal phalanx (van Amstel and Shearer, 2006). This finding probably represents evidence of the developmental process of osseous growths from the abaxial to the axial. This is supported by the general hypothesis that distal phalanx sinking occurs toward the axial and ventral wall of a claw, because of laxity in the collagen fiber attachment between the caudal part of the distal phalanx and the basal layers of the wall epidermis (Greenough and Vermunt, 1991; Lischer et al., 2002; van Amstel and Shearer, 2006). When the distal phalanx has sunk, a greater portion of weight is likely distributed on the

Table 3. Pearson correlation coefficient between age and bone development measures ${ }^{1}$

\begin{tabular}{|c|c|c|c|c|c|c|c|c|}
\hline \multirow[b]{2}{*}{ Group $^{2}$} & \multicolumn{4}{|c|}{ Inner claws } & \multicolumn{4}{|c|}{ Outer claws } \\
\hline & VerBD & Thickness & HorBD ratio & VerBD ratio & VerBD & Thickness & HorBD ratio $^{1}$ & ${\text { VerBD } \text { ratio }^{2}}^{2}$ \\
\hline $\mathrm{T}$ & $0.46^{*}$ & NS & $0.53^{*}$ & $0.48^{*}$ & $0.29^{*}$ & $\mathrm{NS}$ & $0.45^{*}$ & $0.33^{*}$ \\
\hline $\mathrm{F}$ & $0.65^{*}$ & NS & $0.47^{*}$ & $0.68^{*}$ & $0.53^{*}$ & NS & $0.53^{*}$ & $0.51^{*}$ \\
\hline Total & $0.51^{*}$ & NS & $0.51^{*}$ & $0.53^{*}$ & $0.36^{*}$ & NS & $0.46^{*}$ & $0.36^{*}$ \\
\hline
\end{tabular}

${ }^{1}$ VerBD = vertical bone development; Thickness = thickness of subcutis and corium; HorBD ratio = ratio of horizontal bone development; VerBD ratio = ratio of vertical bone development against the subcutis and the corium.

${ }^{2} \mathrm{~T}$ group includes tie-stall housing cows; F group includes both freestall housing and indoor group-housing cows.

$* P<0.01$. 

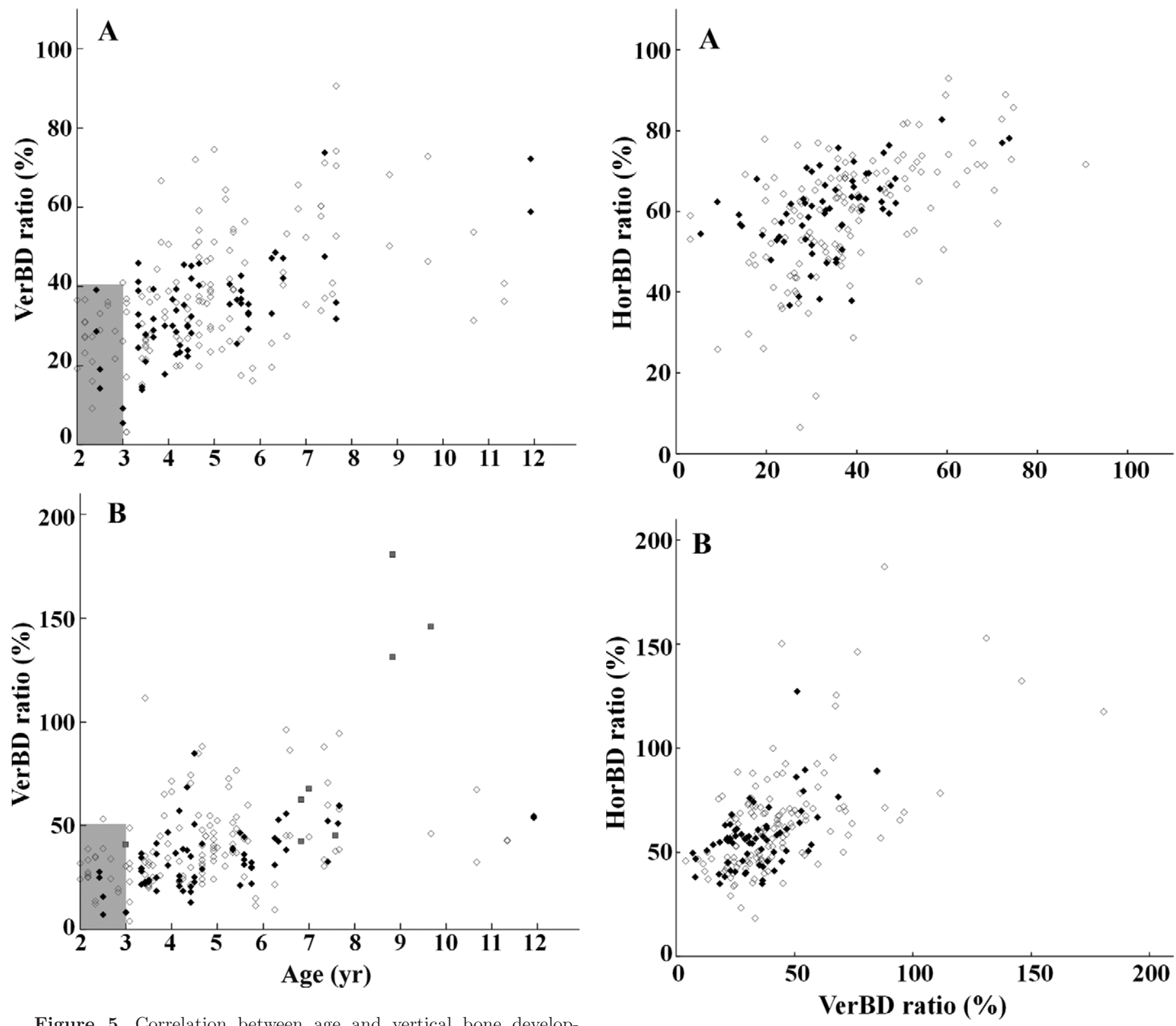

Figure 5. Correlation between age and vertical bone development (VerBD) ratio in inner claws (A) and outer claws (B). Open and filled diamonds represent the $\mathrm{T}$ group (tie-stall housing) and $\mathrm{F}$ group (freestall or indoor group-housing), respectively; gray squares represent affected cases with sole ulcers: 1 case is not shown because the data are beyond the presented graph (age: 88 mo, VerBD ratio: $275.6 \%$ ). Shaded rectangle represents areas of VerBD ratios below 40 and $50 \%$ in the outer and inner claws of 2- to 3-yr-old cattle, respectively.

abaxial side of the suspensory apparatus of the digit bone compared with the axial side. The pattern of moderate bone development exhibited a greater variety of shapes in the caudal aspect of the distal phalanx, seemingly because changes developed according to the increased horizontal bone formation. Abaxial-to-axial bone development horizontally as well as vertically occurred concurrently. This is supported by correlation

Figure 6. Correlation between vertical bone development (VerBD) ratio and horizontal bone development (HorBD) ratio in inner claws (A) and outer claws (B). Open and filled diamonds represent the T group (tie-stall housing) and $\mathrm{F}$ group (freestall or indoor group-housing), respectively.

coefficients between the HorBD and VerBD ratios. In the theoretical mechanism that mechanical pressure due to axial-directional sinking of the distal phalanx is a trigger of ulceration in axial site of the sole (zone 4; Greenough and Vermunt, 1991), the pathological phenomenon may be enhanced by abaxial-to-axial and vertical bone developments, which is likely associated with axial-directional sinking of the distal phalanx.

Increased magnitude of bone development within the tuberculum flexorium correlates with growths on the 
pyramidal process; larger changes often result in ankylosis within the distal interphalangeal joint and swelling of the coronet (Müller et al., 2002; van Amstel and Shearer, 2006). The pyramidal process, the region of insertion of the common digital extensor tendon, becomes irregular with advancing age, and osseous changes are considered normal, as are those on the tuberculum flexorium (Maclean, 1970; Desrochers and Anderson, 2001). Formation of abundant bone in these regions appears to be supported by biomechanic reports that the ground reaction force (GRF) is the force exerted by the ground to the claws in contact with it (van der Tol et al., 2004, 2005), and is directed in vertical and horizontal directions opposite to the contact force of the animal's action (e.g., walking, standing; van der Tol et al., 2005). The horizontal component of GRF likely enhances the mechanical load to the insertion region of the deep digital flexor tendon, but this is reportedly minimized in normal standing because a greater proportion of the GRF is directed vertically. Maintenance of abnormal movement and position likely promotes bone development. On the other hand, when bone formations grow extensively, the lesions may be identical to secondary osseous changes arising from inflammation or infection (Bargai, 1989). In Figure 5B, the data from the cows with sole ulcers are plotted higher than the cows without sole ulcers in the relationships between ages and VerBD ratio. If ulceration occurs on the typical zones of the sole face, then the tuberculum flexorium receives direct exposure to infectious stress via the defective part of the sole face due to ulceration (Greenough and Vermunt, 1991). Sole ulcers cause formations of bone cortex that consist of osteoporotic bone along with exostosis in the ventral surface of the distal phalanx (van Amstel and Shearer, 2006). In the present study, complex osseous changes were observed with increased magnitude of bone formation within the tuberculum flexorium, regardless of presence or absence of sole ulcers (Müller et al., 2002).

The VerBD ratio is dependent on the thickness of the digital cushion to provide shock absorbing capacity. The thickness of the subcutis and the corium (where the digital cushion is mainly occupied) was $6.60 \mathrm{~mm}$ in the inner claws, and $7.22 \mathrm{~mm}$ in the outer claws in the present study. These data supported values of 6 to $10 \mathrm{~mm}$, and slightly thicker in the outer claws than the inner claws (Kofler et al., 1999; Lischer et al., 2002; Räber et al., 2004). The thicker digital cushion in the outer claws compared with the inner claws may be associated with the greater load in the sole and heel regions (Räber et al., 2004). Cows with sole ulcers had significantly thinner digital cushions within both claws compared with healthy cows, supporting previous reports (Lischer et al., 2002; van Amstel and Shearer, 2006). The cows with sole ulcers always possessed extensive bone formations in the ventral surface of the distal phalanx. This caused relative narrowing of the space between the ventral face of the distal phalanx and the inner surface of the horn capsule, leading to a narrowing of the width of the digital cushion. The thickness of the subcutis and the corium was less related to age in the present study and reportedly becomes slightly thinner with increasing age (Räber et al., 2004). Age may be more related to the composition rather than the thickness of the digital cushion. The amount of fat increased up to 2 or 3 parities, and was followed by reduction through replacement of connective tissue. Developmental changes in the different components or shapes and volumes of the digital cushion composed of axial, middle, and abaxial fat pads can be evaluated by radiopaque analysis either using Hounsfield units or by volume rendering on CT images of bovine claws.

The present data suggest that bone development within the tuberculum flexorium may be regarded as close to enthesopathy, distinct from exostosis. Enthesopathy is a stress-related reaction induced by degenerative changes, inflammation, metabolic disorders, and trauma to sites of tendon and ligament attachment to bone. In horses, enthesopathy is well recognized as a common lesion occurring frequently at the palmar process and the facies flexoria (Little and Schramme, 2007; Schramme and Martinelli, 2008). The formations are likely promoted by laminitis-related rotation of the distal phalanx (Little and Schramme, 2007) and bony proliferation reactions against small fractures (Schramme and Martinelli, 2008). In cattle, the small fractures within the tuberculum flexorium are regarded as one of the osseous changes of the distal phalanx occurring through laminitis (e.g., sinking of the distal phalanx and tension of the deep digital flexor tendon; Müller et al., 2002). These lesions cannot be easily detected as laminitic changes without use of imaging methods (Maclean, 1970; Farrow, 1985; Singh et al., 1994), because specific outward findings of the horn capsule suggest a diagnosis of laminitis (Greenough and Vermunt, 1991).

The present data indicate that age is positively correlated with increased horizontal and vertical bone formations within the tuberculum flexorium of inner and outer claws for both types of floor conditions investigated. The age-related development is likely related to exposure time to unnatural conditions and the longterm process of laminitis. Chronic laminitis is a claw disease that progresses silently through a long-term asymptomatic subclinical period (Ossent and Lischer, 1998). The comparative influence of other exacerbating factors arising together with the age-related process can be represented by decreased Pearson correlation 
coefficients between age and bone development measures. Cow comfort in tie-stall housing is dependent on adequate space and time for cows to lie down and rest (Bergsten, 2001). Free walking likely promotes active blood circulation in the peripheral claws, which may be related to a lower level of growth of bone formation (Desrochers and Anderson, 2001). Prolonged standing is one of the most exacerbating factors for sole ulcers (Bergsten, 2001). Lower levels of animal welfare exist in Japanese tie-stall housing systems than in indoor group-housing or freestall housing systems, based on the animal welfare index including the possibility of mobility (e.g., area per animal) and quality of flooring (Seo et al., 2007).

In the present report, heel height and claw width of the outer claw were correlated with HorBD and VerBD ratios. Common causative factors of claw growth include food (dietary protein and energy), season (reduction during winter), floor condition, BW, lactation, and laminitis (Maclean, 1970; Vermunt and Greenough, 1995), but do not include bone development within the tuberculum flexorium. During the enlargement and the increased height of the claw, thickened layers or overgrowth of the corium and the stratum germinativum more commonly occur in outer claws relative to inner claws (Toussaint Raven, 1981). Bone development in the tuberculum flexorium likely has an effect on the mechanical injury to the corium layer, and limits the effect of abnormal change to the shape of the claw, although claw overgrowth may be influenced by the excess growth (e.g., beyond $100 \%$ of HorBD and VerBD ratios). Correlations between heel height and outer claw width and HorBD and VerBD ratios suggest that bone development in the tuberculum flexorium might be associated with the size imbalance between the inner and outer claws. Enlargements of the outer claw could have led to the relative size difference between the inner and outer claws, resulting in an imbalance of weight bearing (Toussaint Raven, 1981; Hoblet and Weiss, 2001). The outer claw receives $70 \%$ of the total force soon after trimming and $80 \%$ before trimming (van der Tol et al., 2004). Regardless of the greater distribution of force against the outer claw, the distal phalanges in outer claws of rear limbs were smaller in size than in inner claws (Ocal et al., 2004).

Quantitative data in the present report can be used as assessment criteria and thus contribute to future assessment of claw lesions through comparisons with measures such as herd health, nutritional factors, and other quantitative measurements from $\mathrm{CT}$ images. Moreover, future applications of CT to clinical cases of lameness will be important in assessing the degree of bone development in the tuberculum flexorium, and how it is related to pain. Pain may be the causative fac- tor that enhances bone development through a vicious cycle that biomechanically alters or prevents normal movement and causes further injury, as well as being the result related to the bone development.

\section{CONCLUSIONS}

The region of sole ulcers depends on where the corium is compressed by the tuberculum flexorium of the distal phalanx, which has a natural downward protruded structure. Mechanical damage to the corium is enhanced by laminitis-related sinking of the distal phalanx, and follows sole hemorrhage and full-thickness breaking of the horn capsule. In the sub-laminitic process, abaxial-to-axial bone development within the tuberculum flexorium likely occurs silently and slowly by increased tension of the deep digital flexor tendon due to sinking of the distal phalanx toward the axial side. The slow progression is supported by the present report describing the osseous change occurring in an age-related manner. Bone development relates to narrowing of the space between the ventral surface of the distal phalanx and the inner surface of the horn capsule, and increasing injurious impact to the corium by the irregular ventral surface of the tuberculum flexorium, which is associated with osteitis. Bone development within the tuberculum flexorium is one possible cause of sole ulceration associated with laminitis. Further research on the relationship between various laminitisrelated changes including dropping and deformation of the distal phalanx using CT can support these findings.

\section{REFERENCES}

Bargai, U. 1989. Radiological diagnosis of the food animals. Pages 29-64 in Bovine Radiography. U. Bargai, J. Pharr, J. P. Morgan, ed. Iowa State University Press, Ames.

Bergsten, C. 2001. Effects of conformation and management system on hoof and leg diseases and lameness in dairy cows. Vet. Clin. North Am. Food Anim. Pract. 17:1-23.

Blowey, R. W., P. Ossent, C. L. Watson, V. Hedges, L. E. Green, and A. J. Packington. 2000. Possible distinction between sole ulcers and heel ulcers as a cause of bovine lameness. Vet. Rec. $147: 110-112$.

Desrochers, A., and D. E. Anderson. 2001. Anatomy of the distal limb. Vet. Clin. North Am. Food Anim. Pract. 17:25-38.

Farrow, C. S. 1985. Digital infections in cattle: Their radiologic spectrum. Vet. Clin. North Am. Food Anim. Pract. 1:53-65.

Greenough, P. R., and J. J. Vermunt. 1991. Evaluation of subclinical laminitis in a dairy herd and observations on associated nutritional and management factors. Vet. Rec. 128:11-17.

Hoblet, K. H., and W. Weiss. 2001. Metabolic hoof horn disease. Claw horn disruption. Vet. Clin. North Am. Food Anim. Pract. $17: 111-127$.

Holzhauer, M., C. Hardenberg, and C. J. M. Bartels. 2008. Herd and cow-level prevalence of sole ulcers in the Netherlands and associated-risk factors. Prev. Vet. Med. 85:125-135.

Kofler, J., P. Kübber, and W. Henninger. 1999. Ultrasonographic imaging and thickness measurement of the sole horn and the underlying soft tissue layer in bovine claws. Vet. J. 157:322-331. 
Lischer, C. J., P. Ossent, M. Räber, and H. Geyer. 2002. Suspensory structures and supporting tissues of the third phalanx of cows and their relevance to the development of typical sole ulcers (Rusterholz ulcers). Vet. Rec. 151:694-698.

Little, D., and M. C. Schramme. 2007. Diagnostic imaging. Pages 141204 in Equine Podiatry. A. E. Floyd, and R. A. Mansmann, ed. Saunders-Elsevier, St Louis, MO.

Maclean, C. W. 1970. A post-mortem X-ray study of laminitis in barley beef animals. Vet. Rec. 86:457-462.

Müller, M., W. Hermanns, M. Feist, S. Hecht, B. Schwarzmann, and K. Nuss. 2002. Pathology of pododermatitis septica profunda Pages 390-393 in Proc. XII Int. Symp. Lameness in Ruminants. Orlando, FL

Murray, R. D., D. Y. Downham, M. J. Clarkson, W. B. Faull, J. W. Hughes, F. J. Manson, J. B. Merritt, W. B. Russell, J. E. Sutherst, and W. R. Ward. 1996. Epidemiology of lameness in dairy cattle: Description and analysis of foot lesions. Vet. Rec. 138:586-591.

Nuss, K., and N. Paulus. 2006. Measurements of claw dimensions in cows before and after functional trimming: A post-mortem study. Vet. J. 172:284-292.

Ocal, M. K., F. Sevil, and U. Parin. 2004. A quantitative study on the digital bones of cattle. Ann. Anat. 186:165-168.

Ossent, P., and C. Lischer. 1998. Bovine laminitis: The lesions and their pathogenesis. In Pract. 20:415-427.

Räber, M., C. H. J. Lischer, H. Geyer, and P. Ossent. 2004. The bovine digital cushion, a descriptive anatomical study. Vet. J. 167:258264.

Raji, A. R., K. Sardari, and H. R. Mohammadi. 2008. Normal crosssectional anatomy of the bovine digit: Comparison of computed tomography and limb anatomy. Anat. Histol. Embryol. 37:188-191.
Schramme, M. C., and M. J. Martinelli. 2008. Collateral desmitis of the coffin joint. Pages 573-578 in Current Therapy in Equine Medicine. N. E. Robinson, ed. Saunders-Elsevier, St Louis, MO.

Seo, T., K. Date, T. Daigo, F. Kashiwamura, and S. Sato. 2007. Welfare assessment on Japanese dairy farms using the Animal Needs Index. Anim. Welf. 16:221-223.

Singh, S. S., W. R. Ward, and R. D. Murray. 1994. An angiographic evaluation of vascular changes in sole lesions in the hooves of cattle. Br. Vet. J. 150:41-52.

Toussaint Raven, E. 1981. Structure and functions of the claw. Pages 13-34 in Cattle Footcare and Claw Trimming. E. Toussaint Raven, ed. Terra Publishing Co., Zutphen, the Netherlands.

van Amstel, S. R., and J. K. Shearer. 2006. Review of pododermatitis circumscripta (ulceration of the sole) in dairy cows. J. Vet. Intern. Med. 20:805-811.

van der Tol, P. P., J. H. Metz, E. N. Noordhuizen-Stassen, W. Back, C. R. Braam, and W. A. Weijs. 2005. Frictional forces required for unrestrained locomotion in dairy cattle. J. Dairy Sci. 88:615-624.

van der Tol, P. P., S. S. van der Beek, J. H. Metz, E. N. NoordhuizenStassen, W. Back, C. R. Braam, and W. A. Weijs. 2004. The effect of preventive trimming on weight bearing and force balance on the claws of dairy cattle. J. Dairy Sci. 87:1732-1738.

Vermunt, J. J., and P. R. Greenough. 1995. Structural characteristics of the bovine claw: Horn growth and wear, horn hardness and claw conformation. Br. Vet. J. 151:157-180. 